\title{
Inhaltsverzeichnis
}

\section{ZUR EINLEITUNG}

Synopse der einzelnen Beiträge. Aspekte der Faktizitätsherstellung in

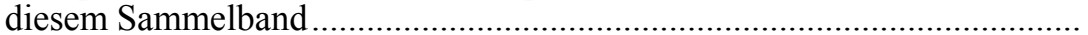

\section{DISKURSANALYTISCHE ANSÄTZE IN DER LINGUISTIK}

\section{Ekkehard Felder}

Faktizitätsherstellung mittels handlungsleitender Konzepte und agonaler Zentren. Der diskursive Wettkampf um Geltungsansprüche ...... 13

\section{Andreas Gardt}

Textanalyse als Basis der Diskursanalyse. Theorie und Methoden

\section{Martin Wengeler}

Aspekte eines gemeinsamen Diskursbegriffs für das Forschungsnetzwerk „Sprache und Wissen“.....

Ingo H. Warnke

Diskurslinguistik und die ,wirklich gesagten Dinge ‘ - Konzepte, Bezüge und Empirie der transtextuellen Sprachanalyse.

Marcus Müller

Wissenskonstituierung in Mündlichkeit und Schriftlichkeit

\section{DISKURSLINGUISTISCHE EINZELFALLSTUDIEN DER FAKTIZITÄTSHERSTELLUNG}

Stephan Habscheid, Nadine Reuther

Performatisierung und Verräumlichung von Diskursen. Zur soziomateriellen Herstellung von ,Sicherheit' an öffentlichen Orten ..... 127

Alexander Ziem

Kognitive Abstraktionsstufen deklarativen Wissens. Evidenz aus korpusbasierten Fallstudien 
Christiane Fellbaum, Ekkehard Felder

Faktizitätsherstellung im Spiegel sprachlicher Ordnung.

Idiomatische Perspektiven-Setzungen im englischen und deutschen

Sterbehilfediskurs

\section{DISKURSANALYSEN AUßERHALB DER LINGUISTIK}

Reiner Keller

Wissenssoziologische Diskursforschung

Martin Gessmann

Vom Ende der Macht des Deklarativen. Michel Foucault nach der

Postmoderne

Peter Wiedemann

Kommunikation von unsicheren Risiken: Ein Problemaufriss

ERINNERN UND VERGESSEN: FAKTIZITÄT IM FOKUS SPRACHLICHER DYNAMIKEN DES WISSENS

\section{Ludwig Jäger}

Erinnern und Vergessen. Zwei transkriptive Verfahren des kulturellen

Gedächtnisses

Matthias Attig

Spuren des Erinnerns und Vergessens in funktionalen Texten

Thorsten Eitz, Martin Wengeler

Vergessene Diskurse? Zur Diskursgeschichte der Weimarer Republik am

Beispiel des Themas Wirtschaft

Alexander Ziem, Ronny Scholz, David Römer

Korpuslinguistische Zugänge zum öffentlichen Sprachgebrauch:

spezifisches Vokabular, semantische Konstruktionen und syntaktische Muster in Diskursen über „Krisen“.

\section{Bettina Radeiski}

Erinnerungen an die DDR oder Erinnerungen an DDR-Propaganda?

Exemplarische Überlegungen zur strukturellen Ähnlichkeit von

Erinnerungs- und Propadandadiskursen

Autorenangaben.

Register. 